\title{
A Coupling Coordination Degree Research of Civil-Military Industrial Integration in Regional Economic Development Based on Industrial Cluster Perspective--Taking Aerospace Manufacturing of Shaanxi as an Example
}

\author{
Chongyi Zhang ${ }^{1}$ \\ ${ }^{1}$ School of Economics and Management, Nanjing University of Aeronautics and Astronautics, Nanjing, China \\ Correspondence: Chongyi Zhang, School of Economics and Management, Nanjing University of Aeronautics \\ and Astronautic, ON.168, Shengtai West Road, Nanjing. E-mail: nhzhangcy@163.com
}

Received: July 6, 2018

Accepted: August 2, 2018

Online Published: August 15, 2018

doi:10.5539/ijef.v10n9p89

URL: https://doi.org/10.5539/ijef.v10n9p89

\begin{abstract}
Based on the principle of coupled cooperation, the article identifies indicators from the perspective of industrial clusters, uses the principal component analysis to extract the effective coupling indicators of military-and-civilian integration industry and regional economic development and builds a model for the coupling coordination between the two. Taking the aerospace manufacturing industry in Shaanxi Province as an example, the article finds that the coupling degree between the aerospace manufacturing industry in Shaanxi Province and the regional economy has been increasing year by year, gradually shifting from disordered development to orderly evolution. Finally, based on empirical conclusions, relevant recommendations are given.
\end{abstract}

Keywords: coupling coordination degree, military and civilian integration industry, regional economy, industrial clusters

\section{Introduction}

The military-civilian integration industry involves many industries such as aviation, spaceflight, shipbuilding, and weapons. It is an important part of China's national economy and plays a decisive role in the development of regional economy. The in-depth advancement of civil-military integration has allowed traditional industrial cities to accelerate their own economic transformation while advancing national defense construction.

Shaanxi Province is a major national defense science and technology province. The national defense industry spans six industries including aviation, aerospace, weapons, electronics, shipbuilding, and nuclear. Among them, the strength of aerospace and equipment manufacturing is particularly prominent (Zhang, 2012). Relying on Xi'an Yanliang National Aviation High-Tech Industrial Base, Xi'an National Civil Aviation Industrial Base and other state-level industrial bases and other types of research institutes, Shaanxi Province has built a number of large-scale and potential enterprise clusters. The province owns $17.80 \%$ of the country's output value of aerospace manufacturing enterprises. In 2015, Shaanxi's aerospace and equipment manufacturing industry's total profit, which greatly promoted the regional economic development.

In recent years, Chinese academia has focused its research on the development if military-civilian integration industries and regional economics in policy formulation, correlation analysis, and simple analysis of coupling coordination. Zhang, Liu, Ma, and $\mathrm{Wu}$ (2011) proposed the combination of national defense construction and regional economic construction from the perspective of top-level design. Zhang and $\mathrm{Li}$ (2011) used the measurement method to verify the relationship between aerospace manufacturing in Shaanxi Province and local economic development, later, a coupling degree model between military and civilian integration industries and regional economic development (Zhang \& $\mathrm{Ai}, 2016$ ). However, due to limitations in its scale, R\&D, and production cycle, the military and civilian integration industry generally adopts a cluster-type development. From the perspective of industrial clusters, there are few articles on the study of military-civilian integration industries and regional economic development, while the main focus is on competitiveness research and related countermeasrues. $\mathrm{Hu}$ and $\mathrm{Li}$ (2014) used grey relational analysis to analyze the factors that enhance the competitiveness of military-civil integration industries. Zhang and Chang (2016) proposed solutions to the 
development of military-civilian integration industries from the perspective of industrial clusters. Based on this, this article based on the perspective of clustering, taking the aerospace manufacturing industry in Shaanxi Province as an example, analyzes the coupling interaction between the military-and-civilian integration industry and the regional economy by constructing a multi-field coupling coordination model.

\section{The Construction of Multi-Index System}

Coupling is the normal correlation between each industry's interdependence and mutual promotion (Xiong \& $\mathrm{Li}$, 2010). Coupling of multiple fields in physics is a related research to solve the problems of superposition and mutual influence of temperature field, stress field and humidity field. In this paper, it mainly refers to the mutual coupling between military-and-civilian integration industrial clusters and regional economy under the influence of multiple indicators.

\subsection{Selection of Indicators}

Based on the principles of quantification, objectivity, prominence, and availability, and summarizing the previous literature, this paper selects 9 indicators of the aerospace manufacturing subsystem and 11 indicators of the regional economic subsystem from the perspective of the industrial cluster (Jiang \& Jia, 2013). The indicators are shown in Table 1.

\subsection{Principal Component Analysis of Regional Economic Indicators}

\subsubsection{Data Processing}

The KMO Bartlett sphere test was performed on the data using the software SPSS 19.0. The results are shown in Table 2.

$\mathrm{KMO}=0.626$, greater than 0.5 , in the Bartlett sphere test, Sig. $=0$, less than 0.05 , so the sample data can be used for factor analysis.

Principal component analysis was performed on the sample data, and a total of 2 principal components were extracted, as show in Table 3. Among them, the first principal component characteristic root is 10.4, the variance contribution rate is $94.543 \%$, the second one is 0.450 , the variance contribution rate is $4.092 \%$, and the former two factors cumulative variance contribution rate is $98.635 \%$.

Table 1 . The coupling index system of aerospace manufacturing industry and regional economy in Shaanxi province

\begin{tabular}{|c|c|c|c|}
\hline Coupling System & Indicator Type & Index Name & Unit of Measurement \\
\hline \multirow{9}{*}{$\begin{array}{c}\text { Aerospace } \\
\text { Manufacturing } \\
\text { Subsystem }\end{array}$} & \multirow{3}{*}{$\begin{array}{l}\text { Cluster } \\
\text { Density }\end{array}$} & The Proportion of Enterprises in the country & $\%$ \\
\hline & & The Proportion of main business income to the country & $\%$ \\
\hline & & The Proportion of total profits in the country & $\%$ \\
\hline & Industrial & Main business income & Billion yuan \\
\hline & Scale & Total Profit & Billion yuan \\
\hline & \multirow{4}{*}{ Creativity } & R\&D Personnel Equivalent to Full-time & Per person per year \\
\hline & & R\&D internal expenditure & Ten thousand yuan \\
\hline & & New Product Sales Revenue & Ten thousand yuan \\
\hline & & Patent Applications & Pieces \\
\hline \multirow{13}{*}{$\begin{array}{l}\text { Regional } \\
\text { Economic } \\
\text { Subsystem }\end{array}$} & \multirow{7}{*}{$\begin{array}{c}\text { Economic } \\
\text { Development }\end{array}$} & GDP & Billion yuan \\
\hline & & \multirow{2}{*}{ The Actual amount of foreign direct investment } & One hundred million \\
\hline & & & US dollars \\
\hline & & Urban and Rural Residents Savings Deposit & Billion yuan \\
\hline & & Public finance income & Billion yuan \\
\hline & & Average wages of employees in urban units & yuan \\
\hline & & Per capita net income of rural households & yuan \\
\hline & \multirow{6}{*}{$\begin{array}{c}\text { Economic } \\
\text { environment }\end{array}$} & New investment in fixed assets & Billion yuan \\
\hline & & Average number of students enrolled in school per 100,000 & \\
\hline & & population & person \\
\hline & & Patent authorization number & piece \\
\hline & & Total freight volume & 10,000 tons \\
\hline & & Highway mileage & kilometers \\
\hline
\end{tabular}


Table 2. KMO and Bartlett's test results

\begin{tabular}{llr}
\hline Sample a sufficient Kaiser-Meyer-Olkin metric & .626 \\
\hline Bartlett's sphericity tese & Approximate Chi-square & 345.321 \\
& df & 55 \\
& Sig. & .000 \\
\hline
\end{tabular}

Table 3. Total variance explained

\begin{tabular}{|c|c|c|c|c|c|c|c|c|c|}
\hline \multirow[b]{2}{*}{ Component } & \multicolumn{3}{|c|}{ Initial feature value } & \multicolumn{3}{|c|}{ Squared extraction } & \multicolumn{3}{|c|}{ Rotation squared } \\
\hline & Total & $\%$ of variance & Accumulation \% & Total & $\%$ of variance & Accumulation \% & Total $\%$ & of varian & ccumulation \\
\hline 1 & 10.400 & 94.543 & 94.543 & 10.400 & 94.543 & 94.543 & 6.212 & 56.475 & 56.475 \\
\hline 2 & .450 & 4.092 & 98.635 & .450 & 4.092 & 98.635 & 4.638 & 42.160 & 98.635 \\
\hline 3 & .103 & .938 & 99.573 & & & & & & \\
\hline 4 & .019 & .174 & 99.748 & & & & & & \\
\hline 5 & .015 & .137 & 99.885 & & & & & & \\
\hline 6 & .006 & .059 & 99.944 & & & & & & \\
\hline 7 & .004 & .035 & 99.979 & & & & & & \\
\hline 8 & .001 & .011 & 99.990 & & & & & & \\
\hline 9 & .001 & .009 & 99.998 & & & & & & \\
\hline 10 & .000 & .001 & 100.000 & & & & & & \\
\hline 11 & $1.323 \mathrm{E}-5$ & .000 & 100.000 & & & & & & \\
\hline
\end{tabular}

xtraction method: Principal component analysis.

\subsubsection{The Determination and Influence of Regional Economic Indicator Fields}

Observe the factor loading matrix and find that the data in each column of the initial composition matrix is not significantly different. Therefore, the factorial maximum method is used to orthogonally rotate the factor axis, and the rotated load matrix is shown in Table 4.

The essence of factor analysis is to classify the original variance according to the level of relevance, so that the same group of variables has a high correlation (Zhang \& Ge, 2016). As can be seen from Table 4, public factor 1 has a comparative effect on GDP, the Actual amount of FDI, new investment in fixed assets, urban and rural residents savings deposit, public finance income, average wages of employees in urban units, per capita net income of rural households, and patent authorization number. These indicators reflect the level of regional economic development and are called economic fields. The public factor 2 has a large load on total freight volume, highway mileage and the average number of students enrolled in school per 100,000 population. These indicators reflect the necessary supporting environment in the region, and are called environment fields. The specific situation is shown in Table 5 .

Table 4. Rotated factor loading matrix

\begin{tabular}{lcc}
\hline & \multicolumn{2}{c}{ Component } \\
\cline { 2 - 3 } GDP & 1 & 2 \\
The Actual amount of FDI & .762 & .644 \\
New investment in fixed assets & .840 & .536 \\
Urban and Rural Residents Savings Deposit & .891 & .441 \\
Public finance income & .763 & .640 \\
Average wages of employees in urban units & .769 & .625 \\
Per capita net income of rural households & .743 & .668 \\
Average number of students enrolled in school per 100,000 population & .844 & .535 \\
Patent authorization number & .572 & .817 \\
Total freight volume & .901 & .415 \\
Highway mileage & .641 & .744 \\
\hline
\end{tabular}

Extraction method :main ingredient.

Rotary method : Orthogonal rotation method standardized with Kaiser.

a. Rotation converges after 3 iterstions. 
Table 5. Regional economic index field

\begin{tabular}{|c|c|c|}
\hline Common Factors & 1 & 2 \\
\hline \multirow{7}{*}{ Explained Indicators } & GDP & total freight volume \\
\hline & the Actual amount of FDI & highway mileage \\
\hline & new investment in fixed assets & $\begin{array}{l}\text { the average number of students enrolled } \\
\text { in school per } 100,000 \text { population }\end{array}$ \\
\hline & $\begin{array}{l}\text { urban and rural residents savings deposit } \\
\text { public finance income }\end{array}$ & \\
\hline & average wages of employees in urban units & \\
\hline & per capita net income of rural households & \\
\hline & patent authorization number & \\
\hline Index Name & economic fields & environment fields \\
\hline Variance Contribution Rate $(\%)$ & 94.543 & 4.092 \\
\hline
\end{tabular}

From a narrow perspective, regional economic development refers to the increase of social wealth in a region. The economic field expresses the concept of narrow regional economic growth. Judging from the classification index of economic fields, 8 indicators such as GDP, new investment in fixed assets and public finance income have reached $94.543 \%$ of the regional economy, which is the main factor affecting regional economic development. Regional economic development is not only reflected in direct economic indicators, indirect environmental indicators also reflect the development of regional economies. Total freight volume, highway mileage and the average number of students enrolled in school per 100,000 population account for $4.092 \%$ of the regional economy, which also reflects the development of regional economy.

\subsection{Principal Component Analysis of Aerospace Manufacturing Indicators}

\subsubsection{Aerospace Manufacturing Index Field Selection}

The sample data for aerospace manufacturing has a KMO 0F 0.673, Bartlett's sphericity test approximates chi-squared $=120.430, \mathrm{Sig} .=0$, and can be used as a factor analysis. With reference to the above method, factor analysis is performed on aerospace manufacturing sample data. Three common factors were extracted and the factor axis was orthogonally rotated using the maximum variance method. The index field of the aerospace manufacturing industry was determined based on the rotated load matrix. The results are shown in Table 6 .

Table 6. Aerospace manufacturing index field

\begin{tabular}{|c|c|c|c|}
\hline Common Factors & 1 & 2 & 3 \\
\hline \multirow{6}{*}{ Explained Indicators } & Main business income & New Product Sales Revenue & $\begin{array}{l}\text { The Proportion of total } \\
\text { profits in the country }\end{array}$ \\
\hline & $R \& D$ internal expenditure & Patent Applications & Total Profit \\
\hline & The Proportion of Enterprises in the & R\&D Personnel Equivalent to & \\
\hline & country & Full-time & \\
\hline & The Proportion of main business & & \\
\hline & income to the country & & \\
\hline Index Name & Scale Field & Technical Field & Benefit Field \\
\hline Variance Contribution rate(\%) & 70.634 & 16.369 & 5.375 \\
\hline
\end{tabular}

Public factor 1 has a greater load on main business income, R\&D internal expenditure, the proportion of enterprises in the country and the proportion of main business income to the country. These indicators reflect the scale of the industry and are defined as scale fields. Factor 2 has a greater load on new product sales revenue, patent applications and R\&D personnel equivalent to full-time. These indicators reflect the technical level and are defined as technical fields. Factor 3 reflects the benefits of the industry and is defined as the benefit field.

\subsubsection{The Impact of Indicator Fields on Industrial Development}

(1) The impact of scale field on industrial development. The aerospace manufacturing industry has high requirements in terms of scale, technology, and funds. The development of the industry often requires the cooperation of a number of production and R\&D units. The clustering of aerospace manufacturing in a certain region can better exert the economies of scale of the industry and improve the joint research and development 
capabilities of the industry. The indicators such as the main business income, the proportion of the number of companies in the country, and the proportion of the main business income in the country reflect the position of the aerospace manufacturing industry in Shaanxi Province. With the further development of China's aerospace manufacturing industry, the "big boss" status of aviation industry in Shaanxi Province will surely be further strengthened, which will help the growth of the industry and promote the development of the regional economy.

(2) The impact of technical field impact on industrial development. Technology is the core of sustainable industrial development and maintaining competitiveness. The new product sales revenue, the number of patent applications, and R\&D personnel equivalent to full-time reflect the investment and harvest of Shaanxi Province in the technical improvement of aerospace manufacturing industry, and are the key indicators for the sustainable development of the industry.

(3) The impact of benefit field impact on industrial development. At present, China's economic development is in a period of transition from extensive to intensive. In the process of continuous optimization and upgrading of industrial structure, backward industries must be eliminated. Profit indicators such as total profits reflect market demand and are an important manifestation of the sustainable development of the industry.

\section{Coupling Coordination Model Construction}

The coupling coordinating view holds that the system follows the evolution from disorder to order. The key to this evolution is the synergy between the various parameters within the system. Coupling is a measure of this synergy. The coupling degree of military-civilian integration industry and regional economy refers to the degree of mutual influence of each element in these two subsystems, revealing the level of synergy between the two, which can be measured by constructing the coupling coordination degree model of the two.

\subsection{Data Standardization Processing and Determination of Indicator Weights}

In order to avoid distortion of the model results due to different data dimension, attributes, etc., the indicators are first standardized by the average and range method. $\mathrm{u}_{\mathrm{i}}(\mathrm{i}=1$ or 2$)$ respectively represent the regional economy and the military-civilian integration industry subsystem. $u_{i j}$ is the $\mathrm{j}$-th indicator in the $\mathrm{i}$-th system, which is obtained after standardization of the original index. The specific formula is as follows:

$$
\begin{gathered}
\mathrm{u}_{\mathrm{i}}=\sum_{\mathrm{j}=1}^{\mathrm{n}} \mathrm{w}_{\mathrm{ij}} \mathrm{u}_{\mathrm{ij}}, \sum_{j=1}^{n} w_{i j}=1(i=1,2) \\
\mathrm{u}_{\mathrm{ij}}=\frac{\mathrm{x}_{\mathrm{ij}}-\min \left(\mathrm{x}_{\mathrm{ij}}\right)}{\max \left(\mathrm{x}_{\mathrm{ij}}\right)-\min \left(\mathrm{x}_{\mathrm{ij}}\right)}
\end{gathered}
$$

The indicators selected in this paper are all positive indicators, and the value of $\mathrm{u}_{\mathrm{ij}}$ is between $[0,1]$.

The weight $\mathrm{w}$ of each indicator is determined by the entropy weighting method. Using the entropy is actually calculated using the information value coefficient of the indicator. The calculation process is as follows:

(1) Calculate the proportion of the $m$-th data value in the $j$-th indicator of the $i$-th system after standardization:

$$
\mathrm{y}_{\mathrm{mj}}=\frac{\mathrm{u}_{\mathrm{ij}}}{\sum_{m=1}^{\mathrm{n}} \mathrm{u}_{\mathrm{ij}}}, 0 \leq \mathrm{y}_{\mathrm{mj}} \leq 1
$$

Get the weight matrix:

$$
Y=\{\mathrm{y} m j\}_{m \times n}
$$

(2) Calculate the information entropy value of the $\mathrm{j}$-th indicator:

$$
e_{j}=-K \sum_{m=1}^{n} y_{m j} \ln y_{m j}, K=\frac{1}{\ln m}
$$

The information utility value $d_{j}$ of an indicator depends on the difference between the information entropy $e_{j}$ and 1 of the indicator, $d_{j}=1-e_{j}$. The value directly affects the weight of the indicator. The larger $d_{j}$ is, the larger the weight of the indicator. The weight of the $j$-th indicator is:

$$
w_{j}=\frac{d_{j}}{\sum_{j=1}^{n} d_{j}}
$$

The weights of the indicators calculated according to the above method are shown in Table 7. 
Table 7. The weight of each indicator in the coupled coordination model

\begin{tabular}{ccc}
\hline Coupling System & Indicator Name & Index Weight \\
\hline & The Proportion of Enterprises in the country & 0.1118 \\
& The Proportion of main business income to the country & 0.1203 \\
The Proportion of total profits in the country & 0.1105 \\
Merospace Manufacturing & Main business income & 0.1093 \\
Subsystem & Total Profit & 0.1143 \\
& R\&D Personnel Equivalent to Full-time & 0.1115 \\
R\&D internal expenditure & 0.1021 \\
New Product Sales Revenue & 0.1180 \\
Patent Applications & 0.1022 \\
GDP & 0.0922 \\
The Actual amount of foreign direct investment & 0.0896 \\
Urban and Rural Residents Savings Deposit & 0.0918 \\
Public finance income & 0.0899 \\
Average wages of employees in urban units & 0.0929 \\
Per capita net income of rural households & 0.0884 \\
New investment in fixed assets & 0.0852 \\
\hline Average number of students enrolled in school per 100,000 & 0.0992 \\
\hline Patent authorization number & Total freight volume & 0.0803 \\
\hline
\end{tabular}

\subsection{Construction of Coupling Coordination Model}

Let $\alpha_{\mathrm{i}}, \beta_{\mathrm{i}}$ be the weights of the $\mathrm{i}$-th indicator of regional economy and military-civilian integration industry respectively. $\mathrm{U}$ and $\mathrm{W}$ are the comprehensive contributions of regional economy and military-civilian integration industry.

$$
U=\partial_{i} \times U_{i}, W=\beta_{i} \times W_{i},
$$

If $\mathrm{U}>\mathrm{W}$, it indicates that the orderly development of regional economy is faster than industrial development, and the economy is in a state of industrial lag; if $\mathrm{W}>\mathrm{U}$, it means that the industrial development is faster than the regional economic development and the economy is in the state of industrial transcendence; if $\mathrm{W}=\mathrm{U}$, then development level of the two systems is equivalent, and the economy is in an industrial synergy state.

In physics, if the variables $\mathrm{u}_{\mathrm{i}}(\mathrm{i}=1,2, \ldots, \mathrm{m}), \mathrm{u}_{\mathrm{j}}(\mathrm{j}=1,2, \ldots, \mathrm{n})$ represent system parameters, respectively, the coupling coordination model of multiple system is:

$$
C_{n}=n\left[\left(u_{1} \bullet u_{2} . . u_{n}\right) \prod\left(u_{i}+u_{j}\right)\right]^{1 / n}
$$

This paper has two systems of regional economy and military-civilian integration industry. This paper takes aerospace manufacturing industry as an example, that is, $n=2$. Therefore, the coupling coordination degree model of this paper is:

$$
C=2\left[(U \bullet W) \prod(U+W)\right]^{1 / 2}
$$

The coupling degree evaluation value $\mathrm{C}$ is between 0 and 1 . The closer $\mathrm{C}$ is to 1 , the greater the coupling between aerospace manufacturing and regional economy, and the two systems achieve benign coupling. Conversely, $\mathrm{C}$ tends to 0 indicates that the coupling degree of the two systems is smaller, and the two systems are in an imbalance state.

The calculation formula of the coupling coordination degree $\mathrm{D}$ is:

$$
D=\sqrt{C \times T}, T=a U+b W
$$

Where $\mathrm{a}$ and $\mathrm{b}$ are undetermined coefficients.

Generally speaking, the evaluation criteria for the coupling degree of military-civilian integration industry and regional economy are shown in Table 8. 
Table 8. Evaluation table of coupling and coordination degree between military-civilian integration industry and regional economy

\begin{tabular}{cccc}
\hline Coordination & Coordination level & Coordination & Coordination level \\
\hline $0-0.09$ & Extreme Imbalance & $0.50-0.59$ & Reluctant coordination \\
$0.10-0.19$ & Serious Imbalance & $0.60-0.69$ & Primary coordination \\
$0.20-0.29$ & Moderate Imbalance & $0.70-0.79$ & Intermediate coordination \\
$0.30-0.39$ & Mild Imbalance & $0.80-0.89$ & Good coordination \\
$0.40-0.49$ & On the verge of Imbalance & $0.90-1.00$ & Quality coordination \\
\hline
\end{tabular}

\section{An Empirical Study on the Coupling Relationship between Aerospace Manufacturing Industry and Regional Economy in Shaanxi Province}

\subsection{Outcome of Practice}

According to relevant research $(\mathrm{Ge}, 2016)$, in the process of coupling and coordinating between military-civilian integration industry and regional economy, the development of military-civilian integration industry will certainly promote the development of regional economy. The sustainable development of regional economy is the result of the interaction of various factors, and the development of military-civilian integration industry is one of the reasons.

Therefore, the regional economy and the military-civilian integration industry are assigned 0.4 and 0.6 respectively. The relevant data is brought into the coupling coordination degree model to obtain the evolution table of the coupling coordination degree between the aerospace manufacturing industry and the regional economy in Shaanxi Province from 2004 to 2015, as shown in Table 9.

Table 9. Evolution table of coupling coordination degree between aerospace manufacturing industry and regional economy in Shaanxi province

\begin{tabular}{ccccccc}
\hline Year & $\mathrm{U}$ & $\mathrm{W}$ & $\mathrm{C}$ & $\mathrm{T}$ & $\mathrm{D}$ & Coordination level \\
\hline 2004 & 0.0003 & 0.2110 & 0.0171 & 0.1267 & 0.0466 & Extreme Imbalance \\
2005 & 0.0427 & 0.1836 & 0.1860 & 0.1272 & 0.1538 & Serious Imbalance \\
2006 & 0.1388 & 0.3071 & 0.3092 & 0.2398 & 0.2723 & Moderate Imbalance \\
2007 & 0.1989 & 0.4024 & 0.3648 & 0.3210 & 0.3422 & Mild Imbalance \\
2008 & 0.2971 & 0.3387 & 0.3978 & 0.3220 & 0.3579 & Mild Imbalance \\
2009 & 0.3937 & 0.3478 & 0.4244 & 0.3581 & 0.3899 & Mild Imbalance \\
2010 & 0.4661 & 0.5212 & 0.4960 & 0.4991 & 0.4976 & On the verge of imbalance \\
2011 & 0.5932 & 0.6106 & 0.5485 & 0.6037 & 0.5754 & Reluctant Coordination \\
2012 & 0.7089 & 0.6695 & 0.5868 & 0.6853 & 0.6341 & Primary Coordination \\
2013 & 0.8169 & 0.7289 & 0.6206 & 0.7641 & 0.6886 & Primary Coordination \\
2014 & 0.9020 & 0.7497 & 0.6398 & 0.8106 & 0.7202 & Intermediate coordination \\
2015 & 0.9861 & 0.6995 & 0.6397 & 0.8142 & 0.7217 & Intermediate coordination \\
\hline
\end{tabular}

\subsection{Empirical Conclusion}

Through the analysis of the coupling and coordination degree between the aerospace manufacturing industry in the military-civilian integration and the regional economy in Shaanxi Province from 2004 to 2015, it is concluded that the coupling degree of the aerospace manufacturing industry in Shaanxi Province and the regional economy is gradually changed from a disordered state to an orderly state. The coupling coordination between the two has been strengthened year by year. 


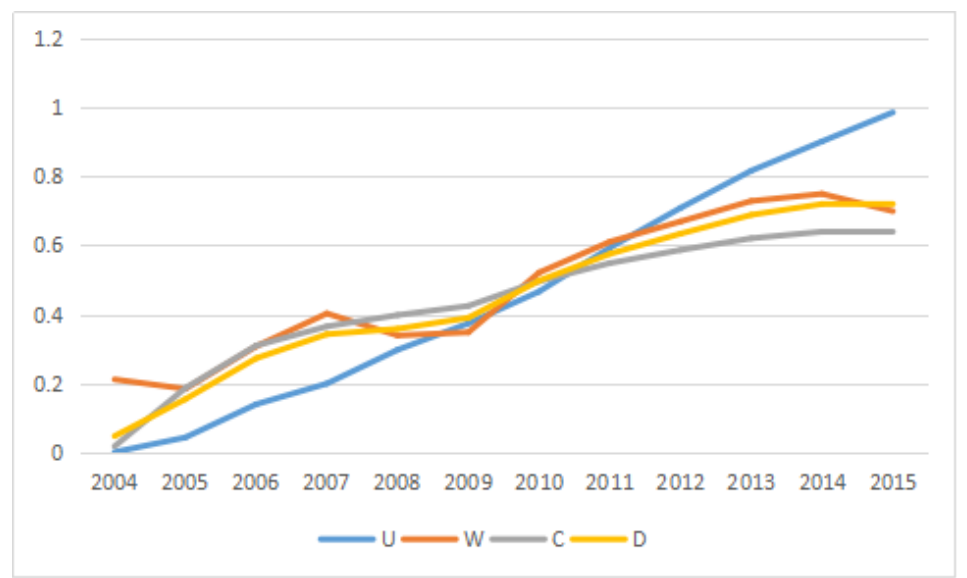

Figure 1. Evolution of coupling coordination degree between aerospace manufacturing industry and regional economy

Observing the weights of various indicators, in the regional economic subsystem, the GDP, urban and rural residents savings deposit, average wages of employees in urban units, average number of students enrolled in school per 100,000 population, total freight volume and highway mileage are more than 0.09 , which has played an important role in promoting regional economic development. In the aerospace manufacturing subsystem, the proportion of main business income to the country, total profit and new product sales revenue account for a large weight. The four indicators have a significant effect on promoting industrial development. All the indicators work together to promote the coupling development of aerospace manufacturing and regional economy.

Before 2009, the comprehensive contribution of the regional economy was less than the comprehensive contribution of the aerospace manufacturing industry, and it was in the economic lag phase. Since 2010, the comprehensive contribution of regional economy has gradually increased, turning into industrial lag, indicating that there is a good interaction between the two.

Before 2010, Shaanxi's aerospace manufacturing and regional economy were in a disorderly development stage. Since 2010, it has been transferred to an orderly stage, and the degree of coupling coordination has interaction and correlation between regional economy and aerospace manufacturing industry is getting deeper and deeper.

\section{Related Recommendations}

The development of regional economy and military-civilian integration industry is in an orderly coupling state, and the degree of correlation between the two is deeper and deeper. Economic and environment fields in the regional economy and scale, innovation and efficiency in the military-civilian integration industry have a deep impact on the development of the two systems. Combined with the empirical conclusions of this paper, the following coupling strategies are proposed:

(1) Enterprises should appropriately expand their business scope and increase their business income. Whether from the principal component analysis of the indicator system or the weight calculation of the coupling coordination degree, the impact of the scale of the aerospace manufacturing industry on the industrial development and regional economy can be seen. The aerospace industry belongs to the high-tech industry and can provide leaps and bounds growth for the regional economy. Therefore, the company can expand its business scope and expands its scale to enable it to develop with the regional economy.

(2) Enterprises continue to increase their talents and technology investment to improve their innovation capabilities. Technological innovation is another important factor affecting the growth of the industry, and technological innovation affects the efficiency of the enterprise by affecting the market competitiveness of the enterprise's products. Enterprises will promote the development of regional economy by increasing the input of talents and technology to achieve effective output.

(3) Local governments should promote the integration of military and civilian industries into industrial parks and achieve cluster development. Industrial clusters can realize the sharing of technology, talents and resources. The development of military-civilian integration industry requires the cooperation of many enterprises in many fields. By building a military-civilian integration industrial base to promote industrial cluster development, local governments can help reduce costs and transaction costs, promote joint innovation of relevant enterprises, and 
promote further coupling between military-civilian integration industrial and regional economies.

\section{Acknowledgements}

Fund project: 2017 Nanjing University of Aeronautics and Astronautics Graduate Open Fund Project: Research on Financial Support System for the Development of Military-Military Integration Industry in China (kfjj20170902).

\section{References}

Hongan, H., \& Yang, L. (2014). Analysis on the Factors Affecting the Competitiveness of China's Military-civilian Integration Industry Cluster_ _ Taking the Western Aerospace Manufacturing Cluster as an Example. Science \& Technology Progress and Policy, (04), 120-124. http://dx.doi.org/10.6049/kjjbydc.2013080589

Hui, Z. (2012). Research on the Development of Military-Civilian Integration from the Perspective of Industrial Agglomeration-Taking Shaanxi Province as an Example. Technology Economics and Management Research, (12), 125-128.

Jing, $\mathrm{G}_{\circ}$ (2016). Research on the coupling principle and evolution model of military-civilian integration and regional economic development. Northwestern Polytechnical University, 2016.

Jinle, Z. (2016). Research on Coupling Coordination Degree of Regional Economic Development Embedded in Military-Military Integration Industry__ Taking Aerospace Manufacturing Industry in Shaanxi Province as an Example. Journal of Nanjing University of Science and Technology (Social Science Edition), (02), 60-64.

Jinle, Z., \& Jing, G. (2016). Research on the embedded regional economic development of military-civilian integration industry under multi-field coupling—-Taking Shaanxi electronic communication and equipment manufacturing industry as an example. Science \& Technology Progress and Policy, (02), 38-42. http://dx.doi.org/10.6049/kjjbydc.2015070767

Jinle, Z., \& Ninghua, C. (2012). Development Countermeasures of Military and Civilian Integration Industry in Shaanxi Province from the Perspective of Industrial Clusters. Journal of Northwestern Polytechnical University (Social Science Edition), (12), 37-40.

Jinle, Z., \& Yufen, L. (2011). An Empirical Study on the Correlation between Aerospace Manufacturing Industry and Local Economic Development in Shaanxi Province. Journal of Northwestern Polytechnical University (Social Science Edition), (09), 19-24.

Minghui, J., \& Xiaohui, J. (2013). The Influence Mechanism and Empirical Study of Industrial Clusters Based on C-D Production Function on Regional Innovation Capability. China Soft Science, (06), 154-161.

Yongqing, X., \& Shicai, L. (2010). Discussion on the Process and Mechanism of the Coupling Development of Strategic Emerging Industries and Traditional Industries. Science of Science and Technology Management, (11), 84-87.

Zhongyuan, Z., Yusong, L., Yuanqing, M., \& Jun, W. (2011). On the Integration of Military and Civil in Regional Economy. Military Economics Research, (03), 12-14.

\section{Copyrights}

Copyright for this article is retained by the author(s), with first publication rights granted to the journal.

This is an open-access article distributed under the terms and conditions of the Creative Commons Attribution license (http://creativecommons.org/licenses/by/4.0/). 